\begin{tabular}{|c|c|c|c|c|c|c|}
\hline Uterine invasion & & & 0.954 & & & 0.397 \\
\hline Yes & $203(90.6)$ & $785(91.4)$ & & $203(88.2)$ & 785 (91.6) & \\
\hline No & $15(6.7)$ & $57(6.6)$ & & $15(8.3)$ & $57(6.3)$ & \\
\hline Not reported & $6(2.7)$ & $17(2.0)$ & & $6(3.5)$ & $17(2.1)$ & \\
\hline Margins on the final specimen & & & 0.424 & & & 0.257 \\
\hline Free & $212(94.6)$ & $800(93.1)$ & & $212(94.1)$ & $800(93.4)$ & \\
\hline Free but close $(<2 \mathrm{~mm})$ or positive & $8(3.6)$ & $49(5.7)$ & & $8(2.7)$ & $49(5.5)$ & \\
\hline Not reported & $3(1.3)$ & $9(1.0)$ & & $3(2.5)$ & $9(1.0)$ & \\
\hline Macroscopic appearance & & & 0.111 & & & 0.595 \\
\hline Exophytic & $100(44.6)$ & $365(42.5)$ & & $100(45.7)$ & $365(43.0)$ & \\
\hline Endophytic ulcerative & $34(15.2)$ & $182(21.2)$ & & $34(14.3)$ & $182(21.0)$ & \\
\hline Endophytic barrel-shaped & $22(9.8)$ & $66(7.7)$ & & $22(8.5)$ & $66(7.4)$ & \\
\hline Histology of the tumor & & & 0.514 & & & 0.231 \\
\hline Squamous carcinoma & $153(68.3)$ & $588(68.5)$ & & $153(71.9)$ & $588(68.1)$ & \\
\hline Adenocarcinoma & $66(29.5)$ & $239(27.8)$ & & $66(26.0)$ & $239(28.3)$ & \\
\hline Adenosquamous carcinoma & $5(2.2)$ & $32(3.7)$ & & $5(2.1)$ & $32(3.5)$ & \\
\hline Tumor grade of differentiation & & & 0.355 & & & 0.456 \\
\hline Grade I & $32(14.3)$ & $132(15.4)$ & & $32(13.3)$ & $132(15.8)$ & \\
\hline Grade II & $89(39.7)$ & $372(43.3)$ & & $89(46.4)$ & $372(43.4)$ & \\
\hline Grade III & 73 (32.6) & $239(27.8)$ & & $73(28.5)$ & $239(28.0)$ & \\
\hline \multicolumn{7}{|l|}{ Characteristics of the proceedure } \\
\hline Uterine manipulator used & & & 0.000 & & & 0.000 \\
\hline Yes & $91(40.6)$ & $631(73.5)$ & & $91(67.0)$ & $631(66.7)$ & \\
\hline No & $94(42.0)$ & $149(17.3)$ & & $94(22.3)$ & $149(22.4)$ & \\
\hline Not reported & $39(17.4)$ & $79(9.2)$ & & $39(10.8)$ & $79(10.9)$ & \\
\hline Surgical approach & & & 0.000 & & & 0.933 \\
\hline Laparoscopic or robotic & $162(72.3)$ & $325(37.8)$ & & $162(45.4)$ & $325(44.9)$ & \\
\hline Open & $62(27.7)$ & $534(62.2)$ & & $62(54.6)$ & $534(55.1)$ & \\
\hline $\begin{array}{l}\text { Surgical experience of surgeon in } \\
\text { charge }\end{array}$ & & & 0.000 & & & 0.783 \\
\hline Fellow in gyn oncology & $3(1.3)$ & $44(5.1)$ & & $3(3.8)$ & $44(4.4)$ & \\
\hline Junion surgeon in gyn oncology & $66(29.5)$ & $135(15.7)$ & & $66(19.7)$ & 135 (18.7) & \\
\hline Senior surgeon in gyn oncology & $155(69.2)$ & $680(79.2)$ & & $155(76.5)$ & $680(76.9)$ & \\
\hline Type of radical hysterectomy performed & & & 0.763 & & & 0.959 \\
\hline Modified radical hysterectomy & $63(28.1)$ & $255(29.7)$ & & $63(24.5)$ & $255(30.7)$ & \\
\hline Classical radical hysterectomy & $151(67.4)$ & $581(67.6)$ & & $151(73.5)$ & $581(66.4)$ & \\
\hline
\end{tabular}

surgical approach. To account for these differences, inverse probability weighting was performed to consider both groups fully comparable.

We used inverse probability weighting to define two comparable groups (sentinel node biopsy vs lymphadenectomy). We performed a logistic regression to calculate the odds of having positive nodes after a sentinel node biopsy compared with a lymphadenectomy in the weighted sample. We also compared the disease-free survival and the overall survival between groups in the weighted cohort.

Result(s)* We found that women who underwent a sentinel node biopsy had smaller tumours and were more using minimally invasive surgery. In the weighted cohort we found that women who underwent a sentinel node biopsy had a $15.7 \%$ of positive nodes vs. 10-7 \% in the lymphadenectomy arm. Sentinel node patients had 1.63-fold higher odds (95\% CI: 1.00-2.64) of having a diagnosis of positive nodes. We did not find that undergoing a sentinel node biopsy had any association neither with disease free survival nor with overall survival.

Conclusion* After applying an Inverse Probability Weighting using a propensity score, the use of Sentinel Lymph Node Biopsy increased the detection of positive nodes by $63 \%$ in the SUCCOR study. The standard pelvic lymphadenectomy might underdiagnose the nodal status in early cervical cancer.

\section{PREVALENCE OF NEW CERVICAL CANCER CASES IN AN ESGO ACCREDITED CANCER CENTER IN ATHENS; A MULTIDISCIPLINARY TUMOR BOARD RETROSPECTIVE ANALYSIS}

C Theofanakis*, A Rountis, E Geramani, E Zachariou, V Theodoulidis, V Pergialiotis, DE Vlachos, N Thomakos, D Haidopoulos, A Rodolakis. University of Athens, Division of Gynaecological Oncology, 1st Department of Obstetrics and Gynaecology, Alexandra Hospital, Athens, Greece

\subsection{6/ijgc-2021-ESG0.65}

Introduction/Background* Cervical cancer represents the fourth most common malignancy in women, with more than half a million new cases each year worldwide. Despite HPV-based screening programs, liquid-based cytology and national vaccination programs, a significant number of patients present with advanced stage disease, beyond the ability to be provided with surgical treatment.

Methodology We conducted a retrospective analysis of new cervical cancer cases presented in our multidisciplinary tumor board from 2005 to 2018. Patients were offered pelvic examination and biopsy, with or without colposcopy. In certain cases, examination under anesthesia was mandatory, in order to assess parametrial involvement. Magnetic resonance imaging of the pelvis and computed tomography of the upper abdomen are part of the obligatory initial investigation for 
assessment of a pelvic tumor and distant spread of the disease. Cervical cancer stages for each patient were modified according to 2018 International Federation of Gynecology and Obstetrics (FIGO) staging for cervical cancer.

Result(s)* A total of 1896 new cervical cancer cases were assessed by our multidisciplinary tumor board in a period of 14 years. Five hundred and eight patients (27\%) were eligible for surgical treatment. Distribution according to stage revealed 62 patients with stage IA2 (12\%), 318 (63\%) IB1, 82(16\%) IB2 and 46 patients (9\%) with stage IIA. Class B radical hysterectomy was performed in 380 patients (75\%), while the rest $128(25 \%)$ underwent a Class C procedure. In all cases, we performed a full bilateral pelvic lymphadenectomy, followed by palpation of para-aortic lymph nodes. We also recorded $90(4.7 \%)$ patients eligible for fertility-sparing treatment, that underwent radical trachelectomy with pelvic lymphadenectomy. The rest 1388 patients were diagnosed with advanced stage disease (IIB-IV) and were referred to definitive concurrent chemoradiation treatment or chemotherapy, followed by radical radiotherapy and brachytherapy.

Conclusion* Designing the optimal treatment for patients diagnosed with cervical cancer demands a multidisciplinary approach, a thorough assessment of the extension of the disease and a detailed consultation for the patient and her family.

\section{THE ANALYSIS OF STATISTICS OF CERVICAL CANCER IN UKRAINE}

L Zrielykh*. Universal Clinic 'Oberig', Center of oncology, Kyiv, Ukraine

\subsection{6/ijgc-2021-ESG0.66}

Introduction/Background* Cervical cancer (CC) takes the fourth place in incidence and mortality rate in women worldwide. In Ukraine cervical cancer occupies the fifth place in the incidence and seventh place in the mortality rate from cancer in female population.

Methodology Analysis of data of Globocan 2020, National cancer registry.

Result(s)* Number of new CC cases in 2015 in Ukraine was 4166, in 2019 - 3936. Number of deaths from CC in 2015 was 1687, in 2019 - 1579 .

Age-standardised incidence rate (world standard) of CC in 2015 was 8,2; in 2019 - 7,6. Age-standardised mortality rate (world standard) in 2015 was 3,1; in 2019 - 2,8.

The relative frequency of cervical cancer incidence in the structure of 10 leading cancer sites in Ukraine in 2015 was $5,9 \%$; in $2019-5,4 \%$ (both $5^{\text {th }}$ place). The relative frequency of CC mortality in the structure of 10 most common cancer sites in Ukraine in 2015 was 5,8\%; in 2019 - 5,9\% (both $7^{\text {th }}$ place).

The relative frequency of cervical cancer incidence in the structure of 5 leading cancer sites in age group 18-29 years in Ukraine in 2015 was $11,8 \%$ ( $3^{\text {rd }}$ place); in $2019-8,1 \%\left(4^{\text {th }}\right.$ place); in age group 30-54 years in 2015 - 13,4\%; in 2019 $12,4 \%$ (both $2^{\text {nd }}$ place).

The relative frequency of cervical cancer mortality in the structure of 5 leading cancer sites in age group 18-29 years in Ukraine in 2015 was 8,4 ; in $2019-13,6 \%$ (both $3^{\text {rd }}$ place); in age group 30-54 years in $2015-14,2 \%$; in $2019-16 \%$ (both $2^{\text {nd }}$ place).

In 2016 patients diagnosed with $4^{\text {th }}$ stage of CC comprised $4,8 \%$, in $2020-9,1 \%$.
Main problems of cervical cancer in Ukraine are the absence of government vaccination programme and lack of women`s adherence for regular screening and treatment.

Conclusion* According to statistical analysis the incidence and mortality rate of CC in 2019 remains at the same level as in the 2015 .

The number of patients with $4^{\text {th }}$ stage has almost doubled in 2020 compared to 2016.

In 2015 CC occupied the $3^{\text {rd }}$ place in the incidence of 5 leading cancer sites in age group 18-29 years, in 2019 this pathology ranks the $4^{\text {th }}$ place, yielding to breast cancer.

\section{OUTCOMES FOLLOWING OPEN RADICAL HYSTERECTOMY AFTER IMPLEMENTATION OF AN ENHANCED RECOVERY AFTER SURGERY (ERAS) PROGRAM}

${ }^{1} \mathrm{~N}$ Agustí ${ }^{*},{ }^{2} \mathrm{M}$ Frumovitz, ${ }^{2} \mathrm{~A}$ Zorrilla-Vaca, ${ }^{3} \mathrm{~B}$ Segarra Vidal, ${ }^{2} \mathrm{R}$ Dos Reis, ${ }^{2} \mathrm{M}$ Iniesta, ${ }^{2} \mathrm{P}$ Ramirez. ${ }^{1}$ Hospital Clínic de Barcelona, Barcelona, Spain; ${ }^{2}$ The University of Texas MD Anderson Cancer Center, Houston, USA; ${ }^{3}$ Hospital La Fe, Valencia, Spain

\subsection{6/ijgc-2021-ESG0.67}

Introduction/Background* Open approach has become the standard for many institutions when performing a radical hysterectomy for early cervical cancer. The objective of this study was to evaluate the length of stay after open radical hysterectomy before and after the implementation of Enhanced Recovery After Surgery (ERAS) pathway in a tertiary cancer center. Methodology This is a retrospective study of patients who underwent open radical hysterectomy for cervical cancer from January 2009 to December 2020. We distinguished two groups based on the time of ERAS implementation: group 1 (pre-ERAS) between January 2009 and October 2014 and group 2 (post-ERAS) between November 2014 and December 2020. We also defined two time periods according to the application of open radical hysterectomy as a standard of care. Univariate analysis was applied and $\mathrm{P}$ values were reported using chi-squared or Fisher's exact test.

Result(s)* A total of 81 patients were included; 29 patients in group 1 and 52 patients in group 2. There were no differences in terms of age (median of 42 years [35-53] in group 1 vs 41 years [35-49] in group $2 ; \mathrm{p}=0.47)$ and BMI $(26.1 \mathrm{~kg} /$

Abstract 771 Table 1 Postoperative outcomes group 1 (preERAS) vs group 2 (post-ERAS)

\begin{tabular}{llll}
\hline Outcome & $\begin{array}{l}\text { Gorup 1 (Pre-ERAS) } \\
2009-2014\end{array}$ & $\begin{array}{l}\text { Group 2 (Post-ERAS) } \\
2015-2020\end{array}$ & P value \\
& $\mathrm{N}=29$ & $\mathrm{~N}=52$ & \\
\hline Hospital stay & $4[3-4]$ & $3[2-3]$ & $<0.01$ \\
Blood transfusion (in-hospital), & $8(27.8 \%)$ & $8(15.4 \%)$ & 0.18 \\
Overall complication events & $13(44.8 \%)$ & $20(38.5 \%)$ & 0.57 \\
Clavien-Dindo & & & \\
None & $16(55.2 \%)$ & $32(61.5 \%)$ & 0.56 \\
I & $6(20.7 \%)$ & $9(17.3 \%)$ & 0.71 \\
II & $6(20.7 \%)$ & $13(25.0 \%)$ & 0.66 \\
III & $1(3.4 \%)$ & $3(5.7 \%)$ & 0.64 \\
IV & $1(3.4 \%)$ & $3(5.8 \%)$ & 0.64 \\
$<30$ days, $\mathrm{n}(\%)$ & & $9(17.3 \%)$ & \\
Readmission & $6(20.7 \%)$ & $1(1.9 \%)$ & 0.40 \\
$>30$ days, $\mathrm{n}(\%)$ & $3(10.3 \%)$ & & 0.05 \\
\hline Readmission & & & \\
\hline
\end{tabular}

